\title{
Technical Note: Reactivity of C1 and C2 organohalogens formation - from plant litter to bacteria
}

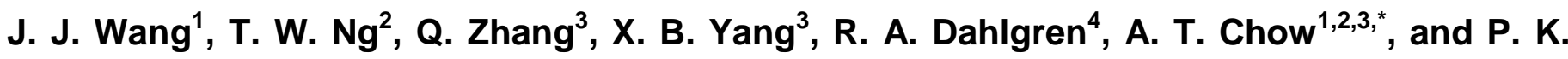 \\ Wong $^{2, *}$
}

[1] Baruch Institute of Coastal Ecology \& Forest Science, Clemson University, Georgetown, South Carolina, USA

[2] School of Life Sciences, The Chinese University of Hong Kong, Shatin N.T., Hong Kong SAR, China

[3] Department of Environmental Science \& Engineering, South China University of Technology, Guangzhou, Guangdong, China

[4] Department of Land, Air and Water Resources, University of California - Davis, California, USA

[*] Correspondence to: A. T. Chow (achow@ clemson.edu) and P. K. Wong (pkwong@cuhk.edu.hk) 
Table S1. The characteristics of seven selected bacteria

\begin{tabular}{|c|c|c|c|c|c|c|c|}
\hline Species & $\begin{array}{l}\text { Acinetobacter } \\
\text { junii (B1) }\end{array}$ & $\begin{array}{l}\text { Aeromonas } \\
\text { hydrophila } \\
\text { (B2) }\end{array}$ & $\begin{array}{l}\text { Bacillus } \\
\text { cereus } \\
\text { (B3) }\end{array}$ & $\begin{array}{l}\text { Bacillus } \\
\text { subtilis (B4) }\end{array}$ & $\begin{array}{l}\text { Escherichia } \\
\text { coli } \\
\text { (B5) }\end{array}$ & $\begin{array}{l}\text { Shigella } \\
\text { sonnei } \\
\text { (B6) }\end{array}$ & $\begin{array}{l}\text { Staphylococcus } \\
\text { sciuri (B7) }\end{array}$ \\
\hline Group & Gram-negative & Gram-negative & Gram-positive & Gram-positive & Gram-negative & Gram-negative & Gram-positive \\
\hline Morphology & Rod & Rod & Rod & Rod & Rod & Rod & Spherical \\
\hline Metabolism & Aerobic & $\begin{array}{l}\text { Facultative } \\
\text { anaerobic }\end{array}$ & $\begin{array}{l}\text { Facultative } \\
\text { anaerobic }\end{array}$ & $\begin{array}{l}\text { Facultative } \\
\text { anaerobic }\end{array}$ & $\begin{array}{l}\text { Facultative } \\
\text { anaerobic }\end{array}$ & $\begin{array}{l}\text { Facultative } \\
\text { anaerobic }\end{array}$ & $\begin{array}{l}\text { Facultative } \\
\text { anaerobic }\end{array}$ \\
\hline Size $(\mu \mathrm{m})$ & $\begin{array}{l}0.9-1.6 \times \\
1.5-2.5\end{array}$ & $\begin{array}{l}0.3-1.0 \times \\
1.0-3.5\end{array}$ & Endospores & Endospores & $\begin{array}{l}1.1-1.5 \times \\
2.0-6.0\end{array}$ & $\begin{array}{l}0.7-1.0 \times \\
1.0-3.0\end{array}$ & $0.5-1.5$ \\
\hline Habitat & $\begin{array}{l}\text { Soil, water, } \\
\text { sewage, and } \\
\text { food }\end{array}$ & $\begin{array}{l}\text { Fresh and } \\
\text { marine waters, } \\
\text { warm-blood } \\
\text { animals }\end{array}$ & $\begin{array}{l}\text { Widely } \\
\text { distributed in } \\
\text { nature. }\end{array}$ & $\begin{array}{l}\text { Widely } \\
\text { distributed in } \\
\text { nature, } \\
\text { primary in } \\
\text { soil }\end{array}$ & $\begin{array}{l}\text { Colon of } \\
\text { human and } \\
\text { warm-blood } \\
\text { animals }\end{array}$ & Soil, water & $\begin{array}{l}\text { Human and } \\
\text { warm-blood } \\
\text { animals; } \\
\text { natural waters }\end{array}$ \\
\hline
\end{tabular}


Table S2. The linear regression between bacterial total organic carbon (TOC) and the bacterial count.

\begin{tabular}{llll}
\hline Bacterial species & Relationship & $\mathrm{n}$ & $\mathrm{R}^{2}$ \\
\hline Acinetobacter junii (B1) & $\mathrm{y}=4.9351 \mathrm{x}-37.377$ & 15 & 0.9970 \\
Aeromonas hydrophila (B2) & $\mathrm{y}=5.0291 \mathrm{x}-45.483$ & 15 & 0.9713 \\
Bacillus cereus (B3) & $\mathrm{y}=2.3581 \mathrm{x}-18.448$ & 15 & 0.9775 \\
Bacillus substilis (B4) & $\mathrm{y}=5.2644 \mathrm{x}-50.018$ & 15 & 0.9856 \\
Escherichia coli (B5) & $\mathrm{y}=5.7935 \mathrm{x}-52.225$ & 15 & 0.9954 \\
Shigella sonnei (B6) & $\mathrm{y}=3.5049 \mathrm{x}-31.618$ & 15 & 0.9493 \\
Staphylococcus sciuri (B7) & $\mathrm{y}=2.2655 \mathrm{x}-18.632$ & 15 & 0.9886 \\
\hline
\end{tabular}

Note: $\mathrm{y}=\mathrm{TOC}(\mathrm{mg}), \mathrm{x}=\lg (\mathrm{D} \times \mathrm{V}) ; \mathrm{D}$ : bacterial density $(\mathrm{cfu} / \mathrm{ml}) ; \mathrm{V}$ : volume $(\mathrm{ml})$ 

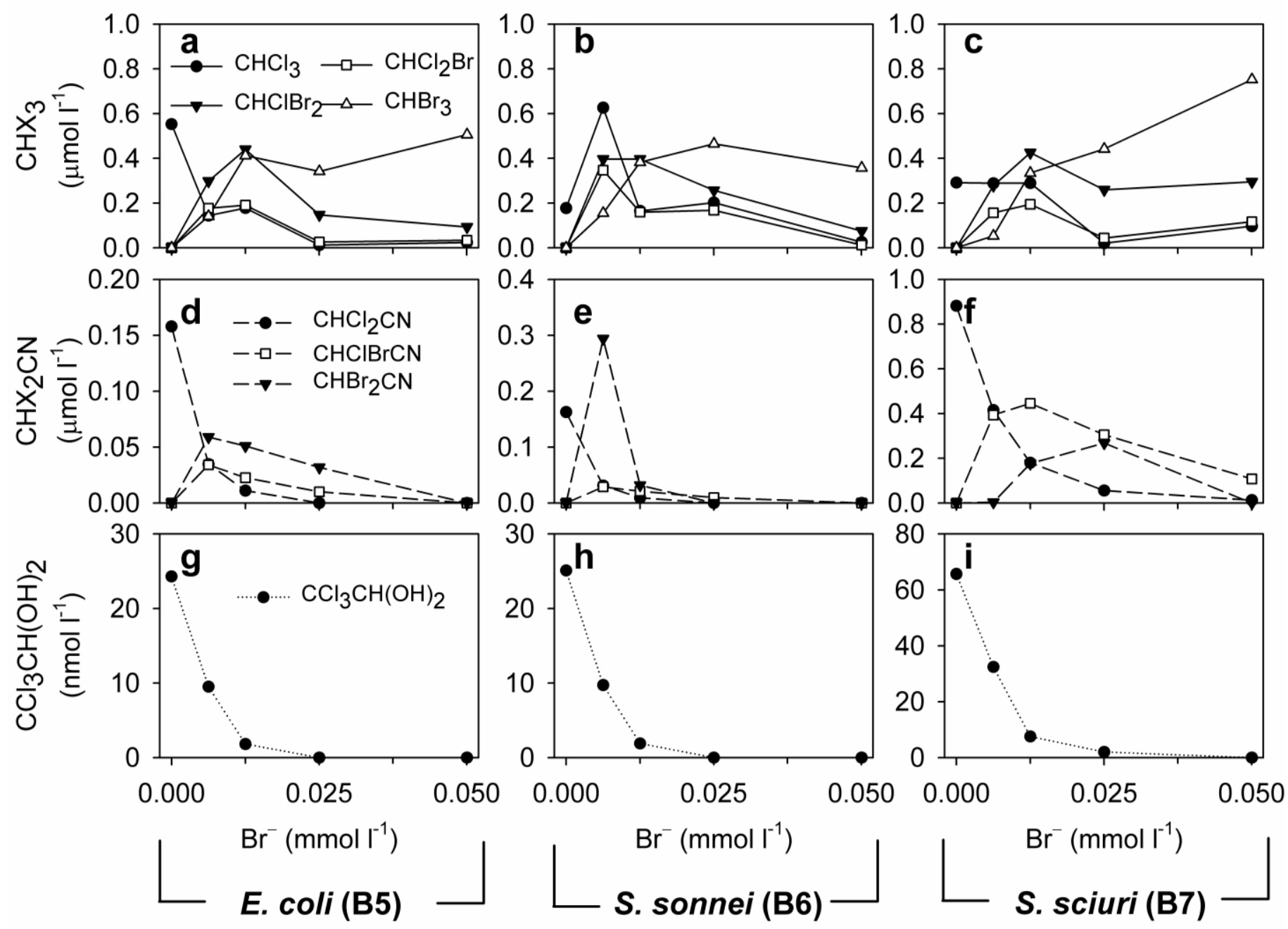

Figure S1 Effects of bromide (at $0,6.25,12.5,25$, and $50 \mu \mathrm{mol} \mathrm{l}^{-1}$ from $\mathrm{KBr}$ ) on organohalogen formation from bacteria B5: Escherichia coli; B6: Shigella sonnei; and B7: Staphylococcus sciuri. 


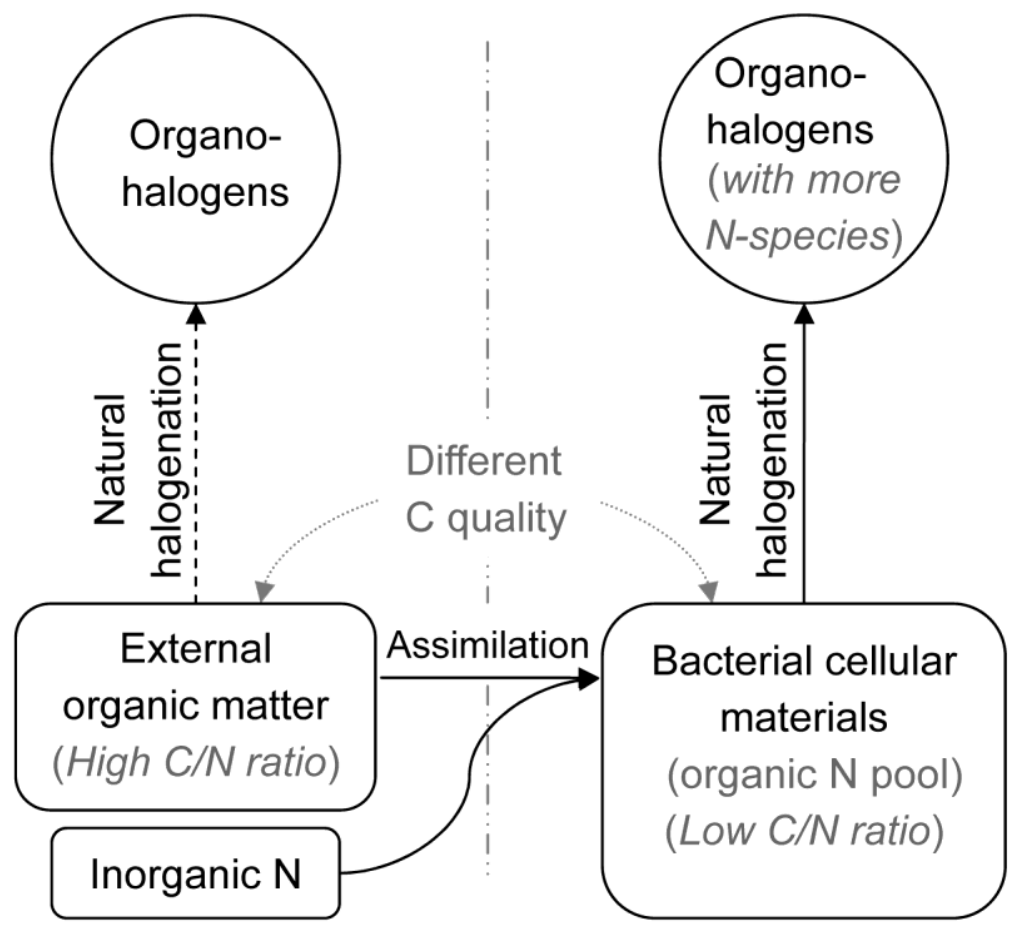

Figure S2. Conceptual model for the impact of bacterial activity on $\mathrm{C}$ and $\mathrm{N}$ cycling during halogenation. 